\title{
Understanding Positive Asymmetric Pricing with a Log-Concave Demand Function and Constant Marginal Costs
}

\author{
Ricardo Quineche ${ }^{1,2}$ \\ ${ }^{1}$ Department of Economics, London School of Economics and Political Science (LSE), London, United Kingdom \\ ${ }^{2}$ Economic Studies, Central Reserve Bank of Peru, Lima, Peru \\ Correspondence: Ricardo Quineche, The Kenneth C. Griffin Department of Economics, The University of Chicago, 1126 \\ E. 59th Street, Chicago, IL 60637, USA.
}

Received: April 16, 2018

doi:10.11114/aef.v5i4.3291

\author{
Accepted: May 20, $2018 \quad$ Available online: May 21, 2018
}

URL: https://doi.org/10.11114/aef.v5i4.3291

\begin{abstract}
The stylized fact of prices increasing more strongly than they decrease in response to identically-sized cost changes, have been confirmed in many empirical studies. However, most of them claim that standard pricing theory cannot account for this phenomenon. Using constant marginal costs and allowing the demand function to be log-concave, this paper shows that the positive asymmetric pricing phenomenon in terms of magnitude can be explained by two of the classic standard economic competition models, Stackelberg with homogenous goods and Bertrand with non-homogenous goods. Furthermore, based on simulations, this paper compares the magnitudes of asymmetry generated in the standard economic competition models. Results show that with a log-concave demand function and constant marginal costs, the magnitude of the positive asymmetric pricing is positively related to the market power. Therefore, the monopoly model is the most asymmetric one, followed by Cournot, Stackelberg and Bertrand.
\end{abstract}

Keywords: Asymmetric price transmission, rockets and feathers, cost pass-through, Monopoly, Cournot, Stackelberg, Bertrand, log-concave demand

\section{Introduction}

"In the paradigmatic price theory that we teach, input price increases or decreases move marginal costs and then price up or down symmetrically and reversibly" (Peltzman, 2000, p.467)

Over the last two decades, many empirical studies have confirmed that in many markets, in response to identically-sized changes in costs, prices often seem to rise more strongly or quickly than they fall (Ward, 1982; Kinnucan \& Forker, 1987; Neumark \& Sharpe, 1992; Borenstein, Cameron \& Gilbert, 1997; Balke, Brown \& Yücel, 1998; Peltzman, 2000; Loy, Holm, Steinhagen \& Glauben, 2015; Loy, Weiss \& Glauben, 2016; Bonnet \& Villa-Boas, 2016). This phenomenon is known as Rockets and Feathers (Note 1), positive asymmetric pricing or positive asymmetric cost pass-through (Note 2). Most of the above papers argue that this phenomenon appears to be inconsistent with conventional standard price theory, and that this pattern represents a failure of (textbook) economics (Peltzman, 2000; Lewis, 2011; Tappata, 2009; Yang \& Ye, 2008; Cabral \& Fishman, 2012). However, following Ritz (2015) and extending it explicitly to the Stackelberg with homogenous goods and Bertrand with non-homogenous goods models, this paper shows through simulations that by allowing the demand function to be log-concave, the standard economic competition models (Note 3) can account for positive asymmetric cost pass-through in terms of magnitude with no need for any further complex settings. Furthermore, simulation analysis also indicates that there is a clear relationship between the magnitude of the positive asymmetric pricing and the market power.

Analysing the positive asymmetric pricing phenomenon is relevant, as it may imply that consumers are not benefiting from a price decrease that, under symmetry, would have been of a greater magnitude. This redistribution of welfare provides a prima facie case for policy intervention. For instance, public institutions such as the European Commission, the Department for Environment, Food and Rural Affairs in the UK, the Competition and Markets Authority in the UK, and in Peru have started looking for the existence of asymmetric cost pass-through in some markets such as agri-food, gasoline and electricity. Given the interest in this phenomenon and its possible ramifications, it is imperative that economists think carefully about the theories they use to explain it. 
The literature about Rockets and Feathers began in the early 1980s in the field of agricultural economics. Since then, a growing empirical literature has shown the existence of asymmetric price transmission for many markets, including fruit and vegetables (Ward, 1982; Pick, Karrenbrock \& Carman, 1990); the dairy sector (Kinnucan \& Froker, 1987; Loy et al., 2015, 2016); pork (Boyd \& Brorsen, 1988); cattle (Bailey \& Brorsen, 1989); banking (Hannan \& Berger, 1991; Neumark \& Sharpe, 1992; Jackson, 1997); coffee (Bonnet \& Villa-Boas, 2016); cereal (Richards, Gómez \& Lee, 2014; Kouyaté \& Cramon-Taubadel, 2016); and gasoline (Note 4) (Bacon, 1991; Karrenbrock, 1991; Borenstein et al., 1997; Balke et al., 1998; Brown \& Yücel, 2000; Verlinda, 2008; Pedriguero-García, 2013) (Note 5).

The most iconic paper of this literature is Peltzman (2000), in which the author found asymmetric pricing in more than two thirds of 77 consumer goods and 165 producer goods. Before Peltzman (2000), most empirical studies attributed the Rockets and Feathers phenomenon to retailers' market power (Note 6) and to adjustment and menu costs (Note 7). However, Peltzman (2000) found that the asymmetric price adjustment was present even in competitive markets and that there was no evidence of a relationship between menu costs and asymmetric cost pass-through. This led him to conclude that the standard economic theory of markets is wrong, because it does not explain the existence of asymmetric cost pass-through.

Since then, some authors have developed new economic theories with the objective of explaining the asymmetric pricing phenomenon. The most recent are the theoretical articles that model the asymmetric cost pass-through as a variation in the intensity of consumer search between regimes of rising and falling prices (Lewis, 2011; Tappata, 2009; Yang \& Ye, 2008; and Cabral \& Fishman, 2012) (Note 8). However, as Ritz (2015) pointed out, the literature on asymmetric pricing to date has not actually tested whether or not simple theory can account for asymmetric pass-through.

Ritz (2015) showed that asymmetric pricing can be modelled using the standard monopoly, Cournot and perfect-competition models if the pricing function is convex in cost. He pointed out that under constant marginal cost, such convexity could arise in the monopoly and Cournot models by changing the assumption of a linear demand function to a log-concave one (Note 9). However, there is still a need for further work to compare these models by the magnitude of the asymmetry.

The contribution of this article is as follows: i) to extend the theoretical framework developed by Ritz (2015) for the positive asymmetric price adjustment pattern in terms of magnitude for the Stackelberg with homogenous goods and Bertrand with non-homogenous goods models; ii) to rank the magnitude of the asymmetry across the monopoly, Cournot, Stackelberg and Bertrand models by simulating the price response for 2116 demand functions to 25 cost shocks, which - at least to the author's knowledge - represents the first simulation-based attempt to study the asymmetric cost pass-through using a log-concave demand function and constant marginal costs.

The results show that: i) the Stackelberg and the Bertrand model can account for the asymmetric cost pass-through phenomenon in terms of magnitude; ii) the magnitude of the positive asymmetric pricing is positively related to the market power, which implies that the monopoly model is the most asymmetric one, followed by Cournot, Stackelberg and Bertrand; and iii) within the Bertrand model, the cross-price demand elasticity and the difference between the goods play an important role in predicting the magnitude of asymmetry, as either a lower value of the former or a higher value of the latter, implies more market power, which translates into a greater magnitude of asymmetry.

This paper is structured as follows. In Section 2, the economic competition models under constant marginal costs and a $\log$-concave demand function are analysed. In section 3, the simulation setup is presented. In section 4, the results are discussed. Finally, Section 5 concludes.

\section{Model Specification}

\subsection{Log-Concave Demand}

Following Ritz's (2015) suggestions, the following log-concave demand function is considered: $P=\alpha-\beta \ln (Q /(1-$ $Q)$ ), which implies that $Q \in(0,1)$ and that the direct demand function is $Q=\left(e^{\frac{\alpha-P}{\beta}}\right)\left(1+e^{\frac{\alpha-P}{\beta}}\right)^{-1}$. According to Ritz, this particular form of the demand function can account for asymmetric cost pass-through in the monopoly and Cournot models. It is worth pointing out that non-explicit proof of this statement was made by Ritz (2015) as he proved the existence of asymmetric pricing in a more general environment by not assuming a particular form for the demand function. This paper presents the proof of this statement for each model analysed in this article in the following subsections, as it is relevant to understanding the functioning of the asymmetric pricing within the models. 


\subsection{Cost Pass-Through}

The cost pass-through $(\rho(c))$ is defined as the ratio of the total change in price $(\Delta P)$ to the total change in cost $(\Delta c)$ : $\rho=\Delta P / \Delta c$ (non-marginal version), $\rho=\mathrm{d} P / \mathrm{d} c$ (marginal version). When the cost pass-through does not depend on $c$, there is no asymmetry, which is the common case when it is assumed that the demand function is linear. However, if the cost pass-through is a function of $c$, there could be either positive or negative asymmetric pricing. If the cost pass-through is an increasing function of $c,(\mathrm{~d} \rho / \mathrm{d} c>0)$, prices increase more strongly than they fall in response to identically-sized cost changes. However, if the cost pass-through is decreasing on $c$, the asymmetric response will be negative (prices fall more strongly that they rise).

\subsection{The Economic Competition Models}

In this section, the five competition models under analysis are described. In general, it is assumed that firms producing in the market have the following cost function: $C\left(q_{i}\right)=c_{i} q_{i}$, which implies constant marginal costs.

\subsubsection{Monopoly}

For the monopoly case, by using the log-concave demand function, the firm maximizes its profits, $\left(\alpha-\beta \ln \left(\frac{\mathrm{Q}}{1-\mathrm{Q}}\right)\right) \mathrm{Q}-$ $c Q$. Then, the firm chooses the level of output that satisfies the first order condition (FOC): $\left(\frac{Q}{1-Q}\right)+\frac{1}{Q(1-Q)}=\frac{\alpha-c}{\beta}$. Once $Q$ is chosen, the price level is determined by the demand function.

Proposition 1: Cost pass-through under the monopoly model, where the demand is log-concave and the marginal cost is constant, is always increasing in cost. Therefore, there is always positive asymmetric pricing.

Proof: Differentiation of the FOC gives $0=\frac{d^{2} P}{d^{2}} Q d Q+2 \frac{d P}{d Q} d Q-d c$, from which, by replacing $\frac{d P}{d Q}=-\frac{\beta}{Q(1-Q)}$ and $\frac{\mathrm{d}^{2} \mathrm{P}}{\mathrm{dQ}^{2}}=\frac{\beta(1-2 \mathrm{Q})}{\mathrm{Q}^{2}(1-\mathrm{Q})^{2}}$, and taking into account that $\rho(\mathrm{c})=\frac{\mathrm{dP}}{\mathrm{dQ}} \frac{\mathrm{dQ}}{\mathrm{dc}}$, the following expression for the pass-through can be obtained: $\rho(c)=\left(1-Q^{*}(c)\right)$. Differentiation of this new expression gives $\frac{d \rho(c)}{d c}=-\frac{d Q}{d c}$, from which plugging in the differentiation of the FOC, $\frac{d Q}{d c}=\frac{d^{2} P}{d Q^{2}} Q+2 \frac{d P}{d Q}$, gives $\frac{d \rho(c)}{d c}=-\left(\frac{d^{2} P}{d Q^{2}} Q+2 \frac{d P}{d Q}\right)^{-1}$. Therefore, by replacing the first and second derivative of the price with respect to the output, the cost pass-through is increasing if $\frac{\beta(1-2 Q)}{Q^{2}(1-Q)^{2}}>-2\left(-\frac{\beta}{Q(1-Q)}\right)$, which holds as $2>1$.

\subsubsection{Cournot}

For the Cournot case, this paper considers there to be two firms in the market that produce a homogenous good, so the total supply is $Q=q_{1}+q_{2}$. Assuming both of them face the same log-concave demand, then each firm maximizes its profits: $\pi_{i}=\left(\alpha-\beta \ln \left(\frac{Q}{1-Q}\right)\right) q_{i}-c_{i} q_{i}$, from which the FOC for firm 1 is $\alpha-\beta \ln \left(\frac{Q}{1-Q}\right)-\beta \frac{q_{1}}{Q(1-Q)}=c_{1}$ and, symmetrically, the FOC for firm 2 is $\alpha-\beta \ln \left(\frac{Q}{1-Q}\right)-\beta \frac{\mathrm{q}_{2}}{\mathrm{Q}(1-\mathrm{Q})}=\mathrm{c}_{2}$. By solving both reaction curves as a non-linear system of equations, the output level for each firm can be found. Then, the price level is obtained by using the demand function.

Proposition 2: Cost pass-through under the Cournot model with two firms, where the demand is log-concave and the marginal cost is constant, is always increasing in cost. Therefore, there is always positive asymmetric pricing.

Proof: Adding both FOC equations and differentiating them gives $0=\frac{\mathrm{d}^{2} \mathrm{P}}{\mathrm{dQ}^{2}} \mathrm{Q} \mathrm{dQ}+3 \frac{\mathrm{dP}}{\mathrm{dQ}} \mathrm{dQ}-2 \mathrm{dc}$, from which, by replacing $\frac{d P}{d Q}=-\frac{\beta}{Q(1-Q)}$ and $\frac{d^{2} P}{d Q^{2}}=\frac{\beta(1-2 Q)}{Q^{2}(1-Q)^{2}}$, and taking into account that $\rho(c)=\frac{d P}{d Q} \frac{d Q}{d c}$, the following expression for the pass-through can be obtained: $\rho(c)=\frac{2\left(1-Q^{*}(c)\right)}{2-Q^{*}(c)}$. Differentiation of this new expression gives $\frac{d \rho(c)}{d c}=-\left(\frac{2}{(2-Q)^{2}}\right) \frac{d Q}{d c}$, 
from which by plugging in the differentiation of the addition of both FOC equations, $\frac{\mathrm{dQ}}{\mathrm{dc}}=\frac{\mathrm{d}^{2} \mathrm{P}}{\mathrm{dQ}^{2}} \mathrm{Q}+3 \frac{\mathrm{dP}}{\mathrm{dQ}}$, gives $\frac{d \rho(c)}{d c}=$ $-\left(\frac{2}{(2-Q)^{2}}\right)\left(\frac{d^{2} P}{d Q^{2}} Q+3 \frac{d P}{d Q}\right)^{-1}$. Therefore, by replacing the first and second derivative of the price with respect to the output, the cost pass-through is increasing if $\frac{d^{2} P}{d Q^{2}} Q+3 \frac{d P}{d Q}<0$, which holds as by construction $Q<2$.

\subsubsection{Stackelberg}

For the Stackelberg case, this paper considers a leader firm (firm 1) and a follower firm (firm 2). As in Cournot, the total output is the sum of both firms' productions. Stackelberg is a sequential game in which firm 1 moves first and then firm 2 moves, so to calculate the Subgame Perfect Nash Equilibrium we must solve the optimization problem backwards. Firm 2 maximizes its profits, $\pi_{2}=\left(\alpha-\beta \ln \left(\frac{q_{1}+q_{2}}{1-\left(q_{1}+q_{2}\right)}\right)\right) q_{2}-c_{2} q_{2}$, from which the FOC is $\alpha-$ $\beta \ln \left(\frac{q_{1}+q_{2}}{1-\left(q_{1}+q_{2}\right)}\right)-\beta \frac{q_{2}}{\left(q_{1}+q_{2}\right)\left(1-\left(q_{1}+q_{2}\right)\right)}=c_{2}$. Generally, from this FOC, the reaction curve for firm 2 can be obtained as $q_{2}=f\left(q_{1}\right)$. Then, firm 1 maximizes its profit by taking the reaction curve of firm 2 as known, $\pi_{1}=\left(\alpha-\beta \ln \left(\frac{q_{1}+f\left(q_{1}\right)}{1-\left(q_{1}+f\left(q_{1}\right)\right)}\right)\right) q_{1}-c_{1} q_{1} \quad, \quad$ from $\quad$ which $\quad$ the $\quad$ FOC $\quad$ is $\alpha-\beta \ln \left(\frac{\mathrm{q}_{1}+\mathrm{f}\left(\mathrm{q}_{1}\right)}{1-\left(\mathrm{q}_{1}+\mathrm{f}\left(\mathrm{q}_{1}\right)\right)}\right)-\beta \frac{\left(1+\mathrm{f}^{\prime}\left(\mathrm{q}_{1}\right)\right)\left(1-\left(\mathrm{q}_{1}+\mathrm{f}\left(\mathrm{q}_{1}\right)\right)\right)-\left(-1-\mathrm{f}^{\prime}\left(\mathrm{q}_{1}\right)\right)\left(\mathrm{q}_{1}+\mathrm{f}\left(\mathrm{q}_{1}\right)\right)}{\left(1-\left(\mathrm{q}_{1}+\mathrm{f}\left(\mathrm{q}_{1}\right)\right)\right)\left(\mathrm{q}_{1}+\mathrm{f}\left(\mathrm{q}_{1}\right)\right)}=\mathrm{c}_{1} \mathrm{q}_{1}$. By solving this equation, we obtain the output level for firm 1, then by plugging it into the reaction curve for firm 2, we obtain $q_{2}$. Finally, by replacing the total output in the demand function, the market price is obtained.

Lemma 1: The marginal cost pass-through under the Stackelberg model with two firms, identical marginal cost and a log-concave demand function equals $\rho(c)=-\frac{\beta}{Q(1-Q)}\left(\frac{\partial q_{1}}{\partial c}+\frac{\partial q_{2}}{\partial q_{1}} \frac{\partial q_{1}}{\partial c}+\frac{\partial q_{2}}{\partial c}\right)$.

Proof: Differentiation of the total output, by taking into account that after solving the optimization problem $q_{1}$ is a function of $c$ and $q_{2}$ is a function of $q_{1}$ and $c$, gives $Q-d c\left(\frac{\partial q_{1}}{\partial c}+\frac{\partial q_{2}}{\partial q_{1}} \frac{\partial q_{1}}{\partial c}+\frac{\partial q_{2}}{\partial c}\right)=0$. Taking into account that $\rho(\mathrm{c})=\frac{\mathrm{dP}}{\mathrm{dQ}} \frac{\mathrm{dQ}}{\mathrm{dc}}$, the new expression of $\rho(c)$ comes immediately after replacing the components.

Proposition 3: Sufficient conditions for the cost pass-through to be increasing in cost under the Stackelberg model with two firms, where the demand is log-concave and the marginal costs are constants and identical for both firms, are: a) $\frac{\partial \mathrm{q}_{2}}{\partial \mathrm{q}_{1}}>0, \frac{\partial \mathrm{q}_{1}}{\partial \mathrm{c}}<0, \frac{\partial \mathrm{q}_{2}}{\partial \mathrm{c}}<0, \frac{\partial^{2} \mathrm{q}_{1}}{\partial \mathrm{c}^{2}}<0, \frac{\partial^{2} \mathrm{q}_{2}}{\partial \mathrm{q}_{1}^{2}}>0$ when $\mathrm{Q}<\frac{1}{2} ;$ or b) $\left(\frac{\partial^{2} \mathrm{q}_{1}}{\partial \mathrm{c}^{2}}+\left(1+\frac{\partial \mathrm{q}_{1}}{\partial \mathrm{c}}\right)\left(\frac{\partial^{2} \mathrm{q}_{2}}{\partial \mathrm{q}_{1}^{2}} \frac{\partial \mathrm{q}_{1}}{\partial \mathrm{c}}+\frac{\partial^{2} \mathrm{q}_{2}}{\partial \mathrm{q}_{1} \partial \mathrm{c}}\right)+\frac{\partial \mathrm{q}_{2}}{\partial \mathrm{q}_{1}} \frac{\partial^{2} \mathrm{q}_{1}}{\partial \mathrm{c}^{2}}\right)>$ $\frac{(1-2 \mathrm{Q})}{\mathrm{Q}(1-\mathrm{Q})}\left(\frac{\mathrm{dQ}}{\mathrm{dc}}\right)^{2}$ when $\mathrm{Q}>\frac{1}{2}$.

Proof: Differentiating the expression for marginal cost pass-through from Lemma 1 with respect to the cost gives $\frac{\mathrm{d} \rho(\mathrm{c})}{\mathrm{dc}}=-\frac{\mathrm{d}^{2} \mathrm{P}}{\mathrm{dQ}^{2}}\left(\frac{\mathrm{dQ}}{\mathrm{dc}}\right)^{2}+\frac{\mathrm{dP}}{\mathrm{dQ}}\left(\frac{\partial^{2} \mathrm{q}_{1}}{\partial \mathrm{c}^{2}}+\left(1+\frac{\partial \mathrm{q}_{1}}{\partial \mathrm{c}}\right)\left(\frac{\partial^{2} \mathrm{q}_{2}}{\partial \mathrm{q}_{1}^{2}} \frac{\partial \mathrm{q}_{1}}{\partial \mathrm{c}}+\frac{\partial^{2} \mathrm{q}_{2}}{\partial \mathrm{q}_{1} \partial \mathrm{c}}\right)+\frac{\partial \mathrm{q}_{2}}{\partial \mathrm{q}_{1}} \frac{\partial^{2} \mathrm{q}_{1}}{\partial \mathrm{c}^{2}}\right) . \quad$ After $\quad$ replacing $\quad \frac{\mathrm{dP}}{\mathrm{dQ}}=-\frac{\beta}{\mathrm{Q}(1-\mathrm{Q})} \quad$ and $\frac{d^{2} P}{d Q^{2}}=\frac{\beta(1-2 Q)}{Q^{2}(1-Q)^{2}}$, the sufficient conditions are immediate.

\subsubsection{Bertrand with Non-Homogenous Goods}

For the Bertrand model, this paper considers two firms, firm 1 and firm 2, that produce two non-homogeneous goods: $q_{1}$ and $q_{2}$, respectively. Each good has its own price $\left(P_{1}\right.$ and $\left.P_{2}\right)$ and both firms decide the price levels simultaneously. It is assumed that each good has its own log-concave demand function: $P_{i}=\alpha_{i}-\beta_{i} \ln \left(\frac{q_{i}}{1-q_{i}}\right)+\delta_{i} P_{-i}$, which implies 
that the direct demand function is $\mathrm{q}_{\mathrm{i}}=\left(\mathrm{e}^{\frac{\alpha_{\mathrm{i}}-\mathrm{P}_{\mathrm{i}}-\delta_{\mathrm{i}} \mathrm{P}_{-\mathrm{i}}}{\beta_{\mathrm{i}}}}\right)\left(1+\mathrm{e}^{\frac{\alpha_{\mathrm{i}}-\mathrm{P}_{\mathrm{i}}-\delta_{\mathrm{i}} \mathrm{P}_{-i}}{\beta_{\mathrm{i}}}}\right)^{-1}=\frac{\Psi_{\mathrm{i}}}{1+\psi_{\mathrm{i}}}$.

In order to decide the price levels, each firm maximizes its profits, $\pi_{i}=P_{i}\left(e^{\frac{\alpha_{i}-P_{i}-\delta_{i} P_{-i}}{\beta_{i}}}\right)\left(1+e^{\frac{\alpha_{i}-P_{i}-\delta_{i} P_{-i}}{\beta_{i}}}\right)^{-1}-$ $c_{i}\left(e^{\frac{\alpha_{i}-P_{i}-\delta_{i} P_{-i}}{\beta_{i}}}\right)\left(1+e^{\frac{\alpha_{i}-P_{i}-\delta_{i} P_{-i}}{\beta_{i}}}\right)^{-1}$, from which the FOC for firm 1 is $\beta_{1}\left(1+e^{\frac{\alpha_{1}-\mathrm{P}_{1}-\delta_{1} \mathrm{P}_{2}}{\beta_{1}}}\right)-\mathrm{P}_{1}+\mathrm{c}_{1}=0$, and, symmetrically, the FOC for firm 2 is $\beta_{2}\left(1+\mathrm{e}^{\frac{\alpha_{2}-\mathrm{P}_{2}-\delta_{2} \mathrm{P}_{1}}{\beta_{2}}}\right)-\mathrm{P}_{2}+\mathrm{c}_{2}=0$. By solving both reaction curves as a non-linear system of equations, the price level for each firm can be found.

Lemma 2: The marginal cost pass-through under the Bertrand model with non-homogenous goods, two firms, identical $c, \alpha$ and $\beta$, and a log-concave demand function equals $\rho_{1}(\mathrm{c})=\frac{1+\Psi_{2}-\delta_{1} \psi_{1}}{1+\Psi_{2}+\Psi_{1}+\left(1-\delta_{1} \delta_{2}\right) \psi_{1} \psi_{2}}$ and $\rho_{2}(c)=\frac{1+\Psi_{1}-\delta_{2} \psi_{2}}{1+\Psi_{2}+\Psi_{1}+\left(1-\delta_{1} \delta_{2}\right) \Psi_{1} \psi_{2}}$, for the price of firm 1 and the price of firm 2 , respectively.

Proof: Differentiation of each FOC gives $0=\left(\psi_{1}+1\right) \mathrm{dP}_{1}-\mathrm{dc}\left(1-\delta_{1} \psi_{1} \frac{\mathrm{dP}_{2}}{\mathrm{dc}}\right)$ and $0=\left(\psi_{2}+1\right) \mathrm{dP}_{2}-\mathrm{dc}(1-$ $\left.\delta_{2} \psi_{2} \frac{d \mathrm{P}_{1}}{\mathrm{dc}}\right)$, respectively (Note 10). Solution of this system of equations gives immediate $\frac{d P_{1}}{d c}$ and $\frac{d P_{2}}{d c}$, which are by definition $\rho_{1}$ (c) and $\rho_{2}(c)$, respectively.

Proposition 4: a) Cost pass-through for the price of firm 1 under the Bertrand model with non-homogenous goods, two firms, identical $c, \alpha$ and $\beta$, and a log-concave demand function, is increasing in cost if $\left(1+\psi_{2}+\psi_{1}+\left(1-\delta_{1} \delta_{2}\right) \psi_{1} \psi_{2}\right)\left(\delta_{1} \psi_{1}-\delta_{2} \psi_{2}\right)-\left(1+\psi_{2}-\delta_{1} \psi_{1}\right)\left(\delta_{2} \psi_{2}+\psi_{1}+\left(1-\delta_{1} \delta_{2}\right) \psi_{1} \psi_{2}+\left(1-\delta_{1} \delta_{2}\right) \psi_{1} \psi_{2} \delta_{2}\right) \geq 0 \quad$ and $\left(1+\psi_{2}+\right.$ $\left.\psi_{1}+\left(1-\delta_{1} \delta_{2}\right) \psi_{1} \psi_{2}\right)\left(\delta_{1}{ }^{2} \psi_{1}-\psi_{2}\right)-\left(1+\psi_{2}-\delta_{1} \psi_{1}\right)\left(\psi_{2}+\delta_{1} \psi_{1}+\left(1-\delta_{1} \delta_{2}\right) \delta_{1} \psi_{1} \psi_{2}+\left(1-\delta_{1} \delta_{2}\right) \psi_{1} \psi_{2}\right) \geq 0$, with at least one strict inequality. b) Cost pass-through for the price of firm 2, under the previous setting, is increasing in cost if $\left(1+\psi_{1}+\psi_{2}+\right.$ $\left.\left(1-\delta_{1} \delta_{2}\right) \psi_{1} \psi_{2}\right)\left(\delta_{2} \psi_{2}-\delta_{1} \psi_{1}\right)-\left(1+\psi_{1}-\delta_{2} \psi_{2}\right)\left(\delta_{1} \psi_{1}+\psi_{2}+\left(1-\delta_{1} \delta_{2}\right) \psi_{1} \psi_{2}+\left(1-\delta_{1} \delta_{2}\right) \psi_{1} \psi_{2} \delta_{1}\right) \geq 0 \quad$ and $\quad\left(1+\psi_{1}+\psi_{2}+(1-\right.$ $\left.\left.\delta_{1} \delta_{2}\right) \psi_{1} \psi_{2}\right)\left(\delta_{2}{ }^{2} \psi_{2}-\psi_{1}\right)-\left(1+\psi_{1}-\delta_{2} \psi_{2}\right)\left(\psi_{1}+\delta_{2} \psi_{2}+\left(1-\delta_{1} \delta_{2}\right) \delta_{2} \psi_{1} \psi_{2}+\left(1-\delta_{1} \delta_{2}\right) \psi_{1} \psi_{2}\right) \geq 0$, with at least one strict inequality.

Proof: For a) and b), the necessary and sufficient conditions follow by differentiating each expression for marginal cost pass-through from Lemma 2 with respect to $c$.

\section{Simulation Setup}

To analyse the asymmetric cost pass-through in the models described in Section 2, this paper simmulates the price response to 25 different values of $c$ that range from 0.1 to 2.5 with increments of 0.1 for each $c$. The simulations were performed by using the Matlab software. For all the models, it is assumed that $c_{1}=c_{2}=c, \alpha_{1}=\alpha_{2}=\alpha$ and $\beta_{1}=\beta_{2}=\beta$. For each model, this paper has generated 2116 different log-concave demand functions such that $\alpha \in[0.5,5.0]$ and $\beta \in[0.5,5.0]$ both of them with increments of 0.1 for each value. Figure 1 shows the demand curve is well-behaved even for extreme values of $\alpha$ and $\beta$.

For the Bertrand model, this paper has considered five scenarios that allow the evaluation of the price responses not only for the case in which both firms charge the same price, but also the cases when there is a differentiated substitution between the two non-homogenous goods and, thus, there are two prices: i) $\delta_{1}=\delta_{2}=0.9$, ii) $\delta_{1}=\delta_{2}=0.95$, iii) $\delta_{1}=$ $\delta_{2}=0.99$, iv) $\delta_{1}=0.99, \delta_{2}=0.95$ and v) $\delta_{1}=0.99, \delta_{2}=0.90$. It is clear from these values that each demand is assumed to be more responsive to own-price.

To solve the optimization decision of the firms, this paper used the fmincon Matlab procedure by minimizing the negative of the profit function with an initial value close to zero. To solve the nonlinear systems of equations, this paper used the Newton-Raphson method (Note 11) that comes incorporated in the Matlab software, with initial values close to zero to ensure convergence. 


\section{Results}

\subsection{Analysing the Outcome of Six Specific Demand Functions}

Before analysing all the simulations results as a group, this paper will focus the analysis on only six demand cases: i) $\alpha=0.5, \beta=1.6$, ii) $\alpha=1, \beta=2$, iii) $\alpha=2, \beta=2.5$, iv) $\alpha=3, \beta=3$, v) $\alpha=4, \beta=3$ and vi) $\alpha=5$, $\beta=4$, for the monopoly, Cournot, Stackelberg and Bertrand with $\delta_{1}=\delta_{2}=\delta$ models.

First, to illustrate whether there is asymmetric pricing or not, and in case there is, whether this is positive or negative, figure 2 shows the non-marginal cost pass-through for the demand cases analysed. It is evident that there is positive asymmetric pricing in the monopoly, Cournot and Stackelberg models as the cost pass-through is increasing with respect to the cost. For the Bertrand cases, the asymmetry is also positive but it appears to be almost non-existent as the slope of the cost pass-through is very close to zero, especially as $\delta$ gets closer to 1 . By construction, in the perfect competition case, there is symmetric pricing; therefore, $\rho(c)$ is completely flat.

Second, in order to determine whether the magnitude of the positive asymmetry depends on the market structure, we need to measure the asymmetry first. As discussed in previous sections, asymmetric pricing means that for an identical percentage increase and decrease in the cost, the percentage change in the price is not identical. To illustrate the asymmetry, this paper is measures it as the percentage deviation between the percentage increase in the price when the cost grows by $\mathrm{x} \%$ with respect to the percentage decrease in the price when the cost falls by $\mathrm{x} \%$. Therefore, a value of $0 \%$ means no asymmetry, a positive percentage indicates positive asymmetry, and a negative percentage represents a negative asymmetry.
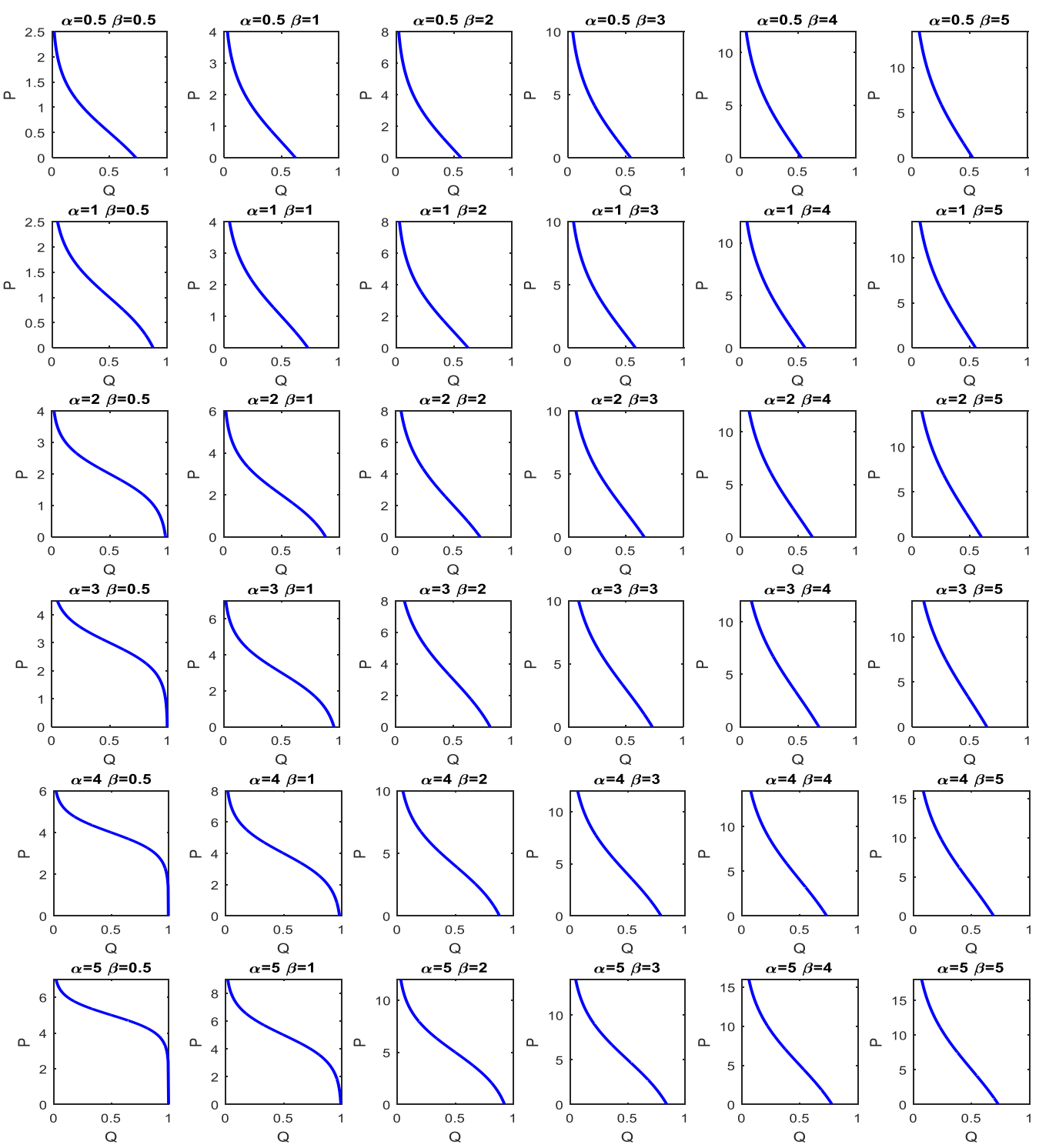

Figure 1. Log-concave demand functions 

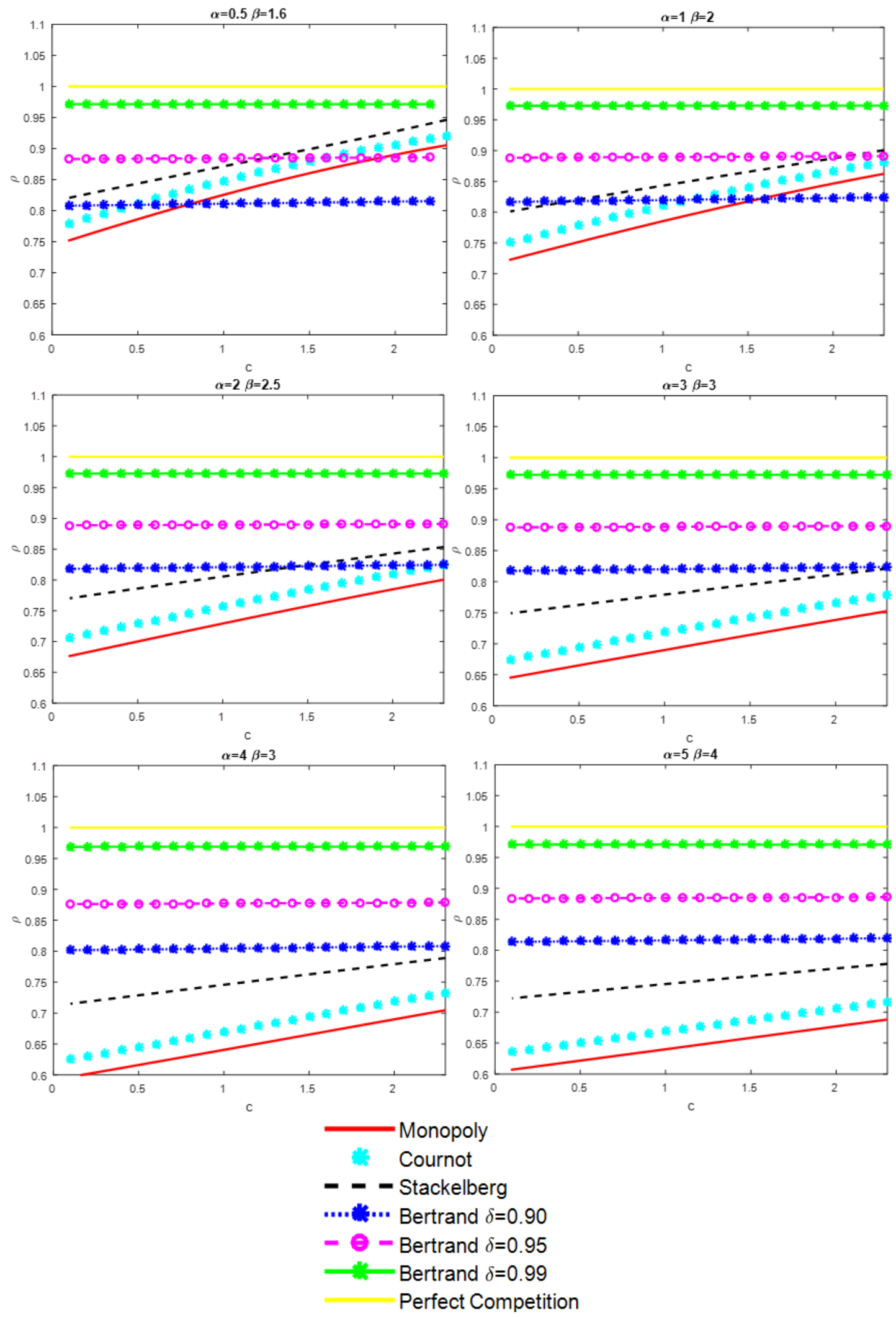

Figure 2. Cost pass-through for six specific demand functions 


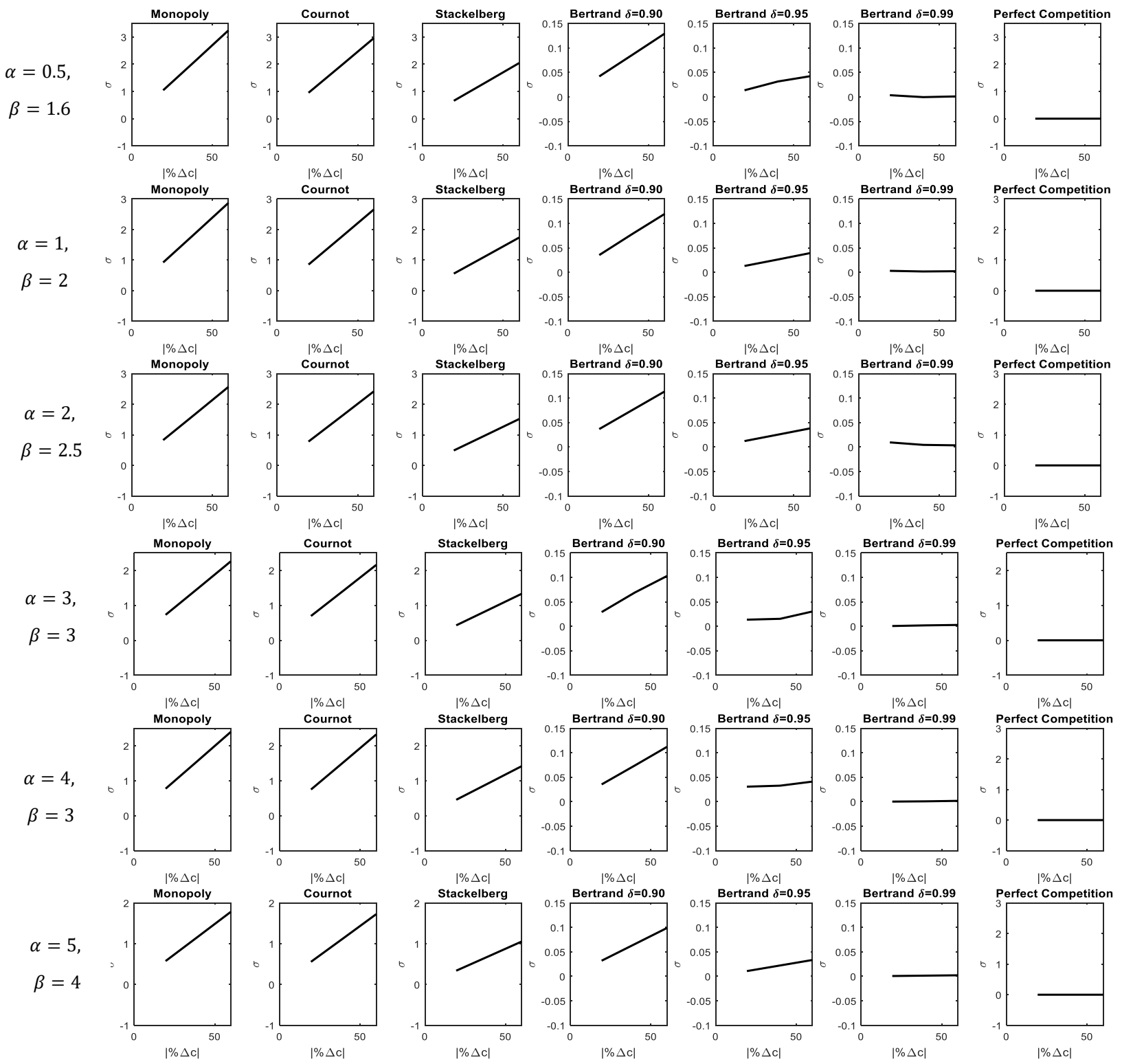

Figure 3. Asymmetry for all cases when $\boldsymbol{c}_{\mathbf{0}}=0.5$

Figures 3 and 4 contain this asymmetry measure for the six demand cases, considering an initial value for the marginal cost, $c_{0}$, of 0.5 and 2.0, respectively (Note 12). Both figures show the most asymmetric model on the left and the most symmetric one (perfect competition scenario) on the right. We can observe from both figures that the magnitude of the asymmetric pricing differs across all models depending not only on the parameter values of the demand function, but on the value of the marginal cost as well. For instance, for an identical 60 percentage increase and decrease when $c_{0}=0.5$, the asymmetry in the monopoly, Cournot and Stackelberg models are $2.87 \%, 2.65 \%$ and $1.74 \%$ respectively when $\alpha=1$ and $\beta=2$; but they are $2.56 \%, 2.42 \%$ and $1.52 \%$, respectively when $\alpha=2$ and $\beta=2.5$.

Even though the magnitudes of the asymmetry do differ, some generalities can be drawn by comparing both figures: a) the monopoly case exhibits the greatest asymmetry, followed by the Cournot, Stackelberg and Bertrand models, respectively, in almost all the cases but for $\alpha=0.5$ and $\beta=1.6$ with $c_{0}=2.0 ; \mathrm{b}$ ) within the Bertrand cases, the closer $\delta$ is to 1 , the closer the magnitude of the asymmetry is to the perfect competition scenario, which means almost non-asymmetry at all. However, in order to determine whether these generalities can hold for the 25 different values of the marginal cost, a new measure that allows comparison of the magnitude of the asymmetry across all models is required. 


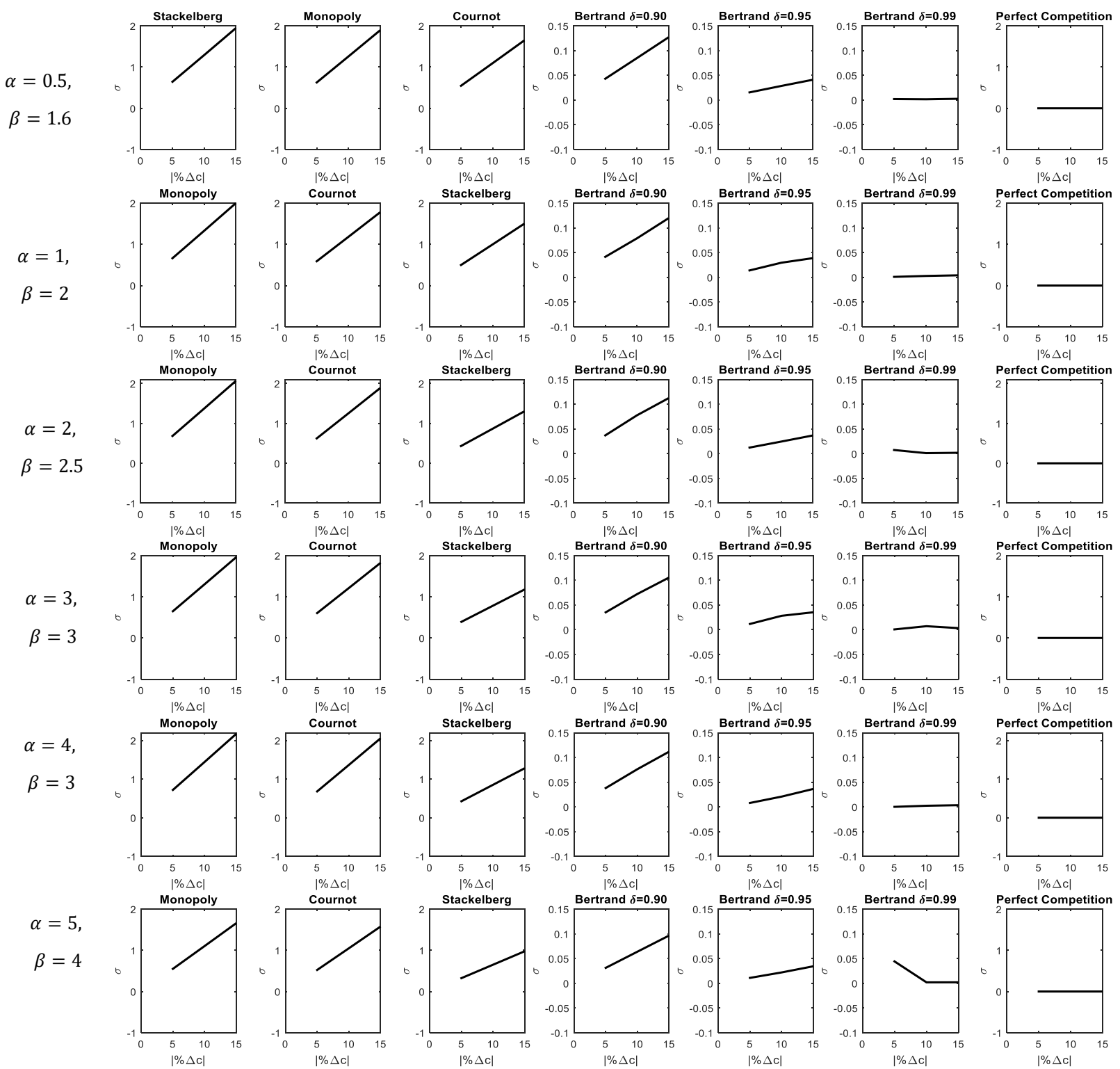

Figure 4. Asymmetry for all cases when $\boldsymbol{c}_{\mathbf{0}}=2.0$

As Ritz (2015) pointed out, the positive (negative) asymmetric cost pass-through needs a pricing function that is convex (concave) in costs. This setup is similar to the risk aversion framework, in which aversion to (love of) risk implies that utility function must be oncave (convex). The similarities for both frameworks are that the first derivate of the function of interest (price and utility, respectively) gives the marginal changes, while the second derivate is not itself a meaningful measure of concavity in economic theory but helps us to identify the type of asymmetric pricing or preferences regarding risk, respectively. Therefore, as the Arrow-Pratt measure of absolute risk-aversion (ARA) is used to compare risk aversion, in order to make a comparison of the asymmetric magnitude, this paper uses the ARA adapted to this framework as follows:

$$
\begin{aligned}
& \gamma=\left|\frac{\frac{\Delta^{2} P}{\Delta c^{2}}}{\frac{\Delta P}{\Delta c}}\right|=\left|\frac{\frac{\Delta \rho}{\Delta c}}{\rho}\right|(\text { non }- \text { marginal version }) \\
& \gamma=\left|\frac{\frac{\mathrm{d}^{2} P}{\frac{d c^{2}}{d P}}}{\frac{d c}{d c}}\right|=\left|\frac{\frac{d \rho}{d c}}{\rho}\right|(\text { marginal version })
\end{aligned}
$$



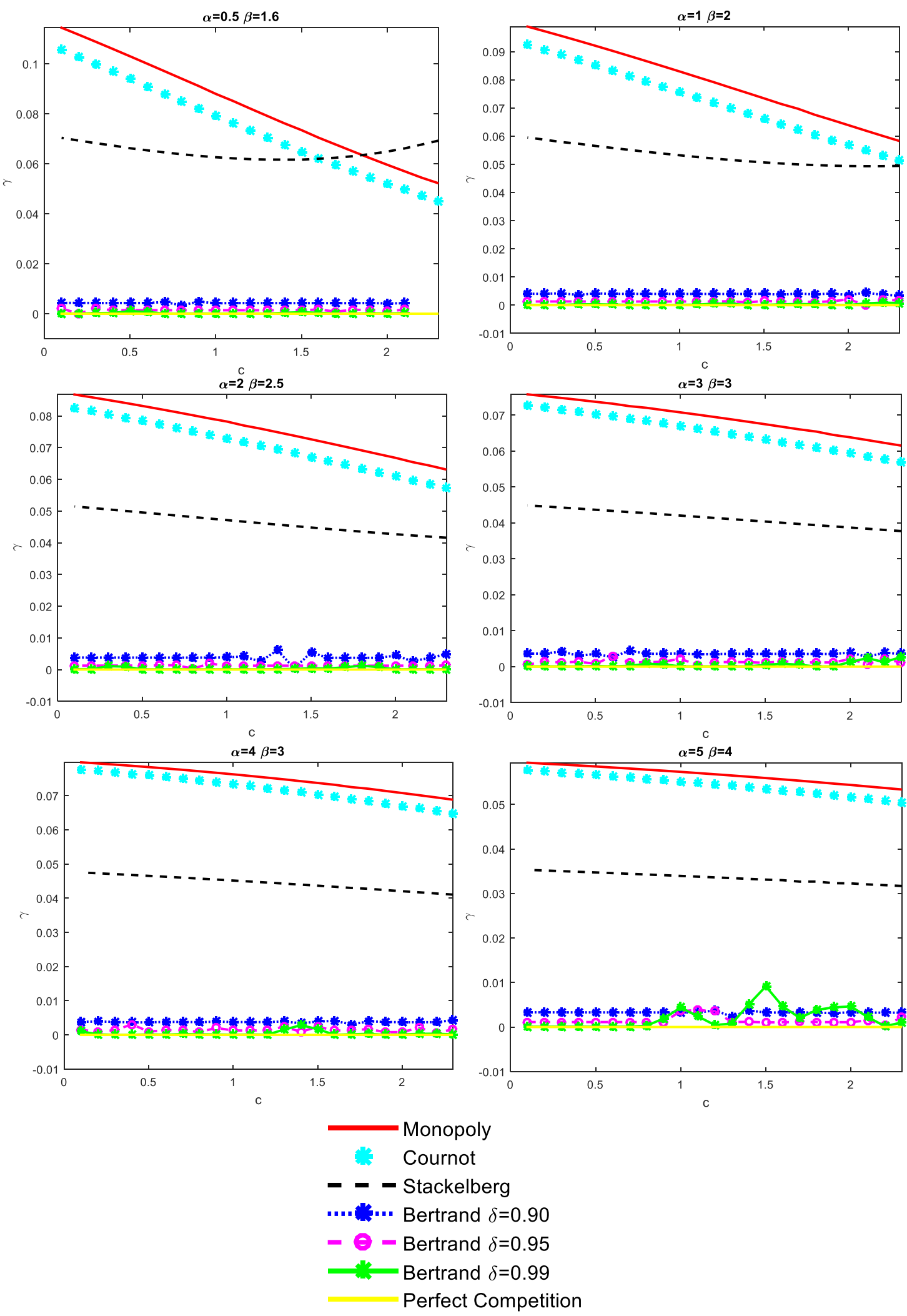

Figure 5. Asymmetry coefficient for all cases

where $\gamma$ is denoted as the asymmetric coefficient and can be considered as the convexity (concavity) of the pricing function at point $c$. The difference between $\gamma$ and the ARA is that the former is the absolute value of the ratio of the second derivate to the first derivate in order to allow all possible combinations of signs to appear. For instance, if the 
first derivate of the pricing function is concave on costs, the ARA could give us both positive and negative values. However, as the objective here is to compare the magnitudes, we require all values to be positive. It is worth pointing out that before using the asymmetric coefficient, we must control by the type of asymmetry we are dealing with (Note 13).

Figure 5 shows how this asymmetry coefficient looks for the six demand functions. As expected, the coefficient captures the findings of figures 3 and 4: for $\alpha=0.5$ and $\beta=1.6$, the most asymmetric model is monopoly when $c=0.5$, and Stackelberg when $c=2.0$, respectively. Moreover, it tells us that if we are in a market where $\alpha=0.5$ and $\beta=1.6$, if $c$ is lower than 1.9, the most asymmetric model is the monopoly; if $\mathrm{c}$ is greater than 1.9, the most asymmetric one is Stackelberg. For each of the other five demand functions, the asymmetric coefficient indicates that we can rank the traditional economic competition models by the magnitude of positive asymmetric pricing as follows: monopoly, Cournot, Stackelberg and Bertrand. Within the Bertrand model, there are some values of $c$ for which the second generality does not hold, especially when $\alpha=5$ and $\beta=4$.

\subsection{Analysing the Price Responses of the 2116 Demand Functions}

Table 1. Frequency count of positive and negative asymmetric pricing cases for all models

\begin{tabular}{lccc}
\hline Model & & $\Delta \rho / \Delta c>0$ & $\Delta \rho / \Delta c<0$ \\
\cline { 1 - 1 } \cline { 4 - 4 } Monopoly & & 1.000 & 0.000 \\
Cournot & & 1.000 & 0.000 \\
Stackelberg & & 1.000 & 0.000 \\
Bertrand $\delta_{1}=\delta_{2}=\delta=0.90$ & & 0.993 & 0.007 \\
Bertrand $\delta_{1}=\delta_{2}=\delta=0.95$ & & 0.960 & 0.040 \\
Bertrand $\delta_{1}=\delta_{2}=\delta=0.99$ & & 0.820 & 0.180 \\
Bertrand F1, $\delta_{1}=0.99, \delta_{2}=0.95$ & & 0.908 & 0.092 \\
Bertrand F2, $\delta_{1}=0.99, \delta_{2}=0.95$ & & 0.916 & 0.084 \\
Bertrand F1, $\delta_{1}=0.99, \delta_{2}=0.90$ & & 0.968 & 0.032 \\
Bertrand F2, $\delta_{1}=0.99, \delta_{2}=0.90$ & & 0.999 & 0.001 \\
\hline
\end{tabular}

Note: Bertrand F1 denotes results associated with the price chosen by firm 1 in the Bertrand model, while Bertrand F2 denotes the ones associated with firm 2 .

First, as we expected, Table 1 confirms that just by changing the assumption of the demand form, asymmetric pricing emerges as a natural response in the very well-known economic competition models. For all the models and given the parameter values for the simulations, positive asymmetry seems to be the norm. For the monopoly, Cournot and Stackelberg models, positive asymmetry is found in all cases. Within the Bertrand model, we can see that the positive asymmetry is more frequent when: a) given that the cross-price elasticity is identical for both demands $\left(\delta_{1}=\delta_{2}=\delta\right)$, this coefficient gets lower (i.e. when $\delta=0.99,82 \%$ of the cases present positive asymmetry, but when $\delta=0.90$, this percentage increases to 99.3\%); and b) when the goods are more differentiated (i.e. when $\delta_{1}=0.99$ and $\delta_{2}=0.95$, $90.8 \%$ and $91,6 \%$ of the cases present positive asymmetry in the price adjustment for firm 1 and 2, respectively, but when $\delta_{1}=0.99$ and $\delta_{2}=0.90$, those percentages increase to $96.8 \%$ and $99.9 \%$, respectively). Some intuition can be added to these results, as both, a lower value of $\delta$ when $\delta_{1}=\delta_{2}=\delta$, and a greater difference between $\delta_{1}$ and $\delta_{2}$, are scenarios of lower substitution between the goods, which can be interpreted as scenarios of greater market power for the firms. Therefore, the simulation results may be reflecting that for the Bertrand model, higher market power translates into a greater number of positive asymmetric-pricing cases.

Second, in order to find out which model generates the most positive asymmetric price response, this paper calculates the asymmetry coefficient described in the previous subsection for all cases where positive asymmetry is found. Tables 2, 3 and 4 show the comparison of this coefficient between the models with homogenous goods, models with homogenous goods and Bertrand when the price chosen by both firms is the same $\left(\delta_{1}=\delta_{2}\right)$, and within Bertrand scenarios, respectively. For a more detailed analysis, the results in all these tables are subdivided by some levels of the marginal cost and $\alpha$. 
Table 2. Frequency count of possible scenarios comparing the monopoly, Cournot and Stackelberg models

\begin{tabular}{|c|c|c|c|c|c|c|}
\hline$\curlyvee$ & $0.5 \leq \alpha \leq 5$ & $0.5 \leq \alpha \leq 1$ & $1.1 \leq \alpha \leq 2.0$ & $2.1 \leq \alpha \leq 3.0$ & $3.1 \leq \alpha \leq 4.0$ & $4.1 \leq \alpha \leq 5.0$ \\
\hline \multicolumn{7}{|l|}{ For $0.1 \leq c \leq 2.5$} \\
\hline Monopoly $>$ Cournot $>$ Stackelberg & 0.980 & 0.884 & 0.976 & 1.000 & 1.000 & 1.000 \\
\hline Monopoly $>$ Stackelberg $>$ Cournot & 0.005 & 0.029 & 0.008 & 0.000 & 0.000 & 0.000 \\
\hline Stackelberg $>$ Monopoly $>$ Cournot & 0.015 & 0.087 & 0.017 & 0.000 & 0.000 & 0.000 \\
\hline \multicolumn{7}{|l|}{ For $2.0 \leq c \leq 2.5$} \\
\hline Monopoly > Cournot $>$ Stackelberg & 0.934 & 0.670 & 0.893 & 1.000 & 1.000 & 1.000 \\
\hline Monopoly $>$ Stackelberg $>$ Cournot & 0.016 & 0.073 & 0.031 & 0.000 & 0.000 & 0.000 \\
\hline Stackelberg $>$ Monopoly $>$ Cournot & 0.050 & 0.258 & 0.076 & 0.000 & 0.000 & 0.000 \\
\hline \multicolumn{7}{|l|}{ For $1.0 \leq c \leq 1.9$} \\
\hline Monopoly > Cournot $>$ Stackelberg & 0.980 & 0.866 & 0.987 & 1.000 & 1.000 & 1.000 \\
\hline Monopoly $>$ Stackelberg $>$ Cournot & 0.006 & 0.036 & 0.006 & 0.000 & 0.000 & 0.000 \\
\hline Stackelberg $>$ Monopoly $>$ Cournot & 0.014 & 0.098 & 0.008 & 0.000 & 0.000 & 0.000 \\
\hline \multicolumn{7}{|l|}{ For $0.1 \leq c \leq 0.9$} \\
\hline Monopoly $>$ Cournot $>$ Stackelberg & 1.000 & 0.998 & 1.000 & 1.000 & 1.000 & 1.000 \\
\hline Monopoly $>$ Stackelberg $>$ Cournot & 0.000 & 0.001 & 0.000 & 0.000 & 0.000 & 0.000 \\
\hline Stackelberg $>$ Monopoly $>$ Cournot & 0.000 & 0.000 & 0.000 & 0.000 & 0.000 & 0.000 \\
\hline
\end{tabular}

From Table 2, it can be appreciated that the market power is reflected in the magnitude of the asymmetry as, in $98 \%$ of all cases, the asymmetric coefficient in the monopoly model is the greatest, followed by Cournot and Stackelberg. This result is robust for any level of marginal cost and $\alpha$. This is a very intuitive result as in an environment of non-competition, the firm(s) can take advantage of this market power by not only setting a higher price (Note 14) but also by increasing the price more strongly than decreasing it in response to an identically-sized cost change.

In addition, it is intended to add the Bertrand with non-homogenous goods model to the previous comparison. In a very strict sense, they are different models and in general comparing them will be like comparing potatoes with chickens. However, a comparison between them is still valid and relevant as when $\delta_{1}=\delta_{2}$, the goods are homogenous, so just one price arises. Therefore, under this scenario, the Bertrand model looks like the Cournot model but with the price as the control variable instead of the output level (Note 15). The comparison results shown in Table 3 indicates that in general the Bertrand model is the least asymmetric one with a frequency count of occurrence greater than $96 \%$. Again, this is a very intuitive result as it reflects the fact that in the Bertrand model, when a firm is deciding the price level for its good, the firm has to take into account that consumers are willing to buy the identical good to the other firm, which may be offering it at a lower price. Therefore, the mere existence of cross-price demand elasticity translates into less market power, which results in a small magnitude of asymmetric pricing.

The comparison within the Bertrand model can be found in Table 4, from which some generalities can be inferred. First, it can be observed that for the homogeneous case, the asymmetry magnitude is inversely related with the value of $\delta$ as Bertrand with $\delta=0.90$ is the most asymmetric, followed by Bertrand with $\delta=0.95$ and Bertrand with $\delta=0.99$ in $91.7 \%$ of the cases. As $\delta$ captures the impact that one price firm has on the demand of the other good, these results reflect the fact that the smaller the substitution between the goods is, the greater the market power the firm has, which results in a greater magnitude of asymmetric pricing.

Second, for the non-homogenous case, the simulation results show that the number of cases in which the price of firm 2 is more asymmetric than the price of firm 1 increases from $77.1 \%$ to $99.9 \%$ when $\delta_{2}$ gets smaller than $\delta_{1}$. As a smaller value $\delta_{i}$ translates into a smaller cross-price demand elasticity for firm $i$, the intuition of this result is that the firm that has the lower cross-price demand elasticity, has more market power, and, thus, takes advantage of this situation by imposing the highest positive asymmetric price adjustment. 
Table 3. Frequency count of possible scenarios comparing the monopoly, Cournot, Stackelberg and Bertrand $\left(\delta_{1}=\delta_{2}\right)$ models

\begin{tabular}{|c|c|c|c|c|c|c|}
\hline$\curlyvee$ & $0.5 \leq \alpha \leq 5$ & $0.5 \leq \alpha \leq 1$ & $1.1 \leq \alpha \leq 2.0$ & $2.1 \leq \alpha \leq 3.0$ & $3.1 \leq \alpha \leq 4.0$ & $4.1 \leq \alpha \leq 5.0$ \\
\hline Monopoly $>$ Cournot $>$ Stackelberg $>$ Bertrand $(\delta=0.90)$ & 0.995 & 0.977 & 1.000 & 1.000 & 0.999 & 0.995 \\
\hline Stackelberg $>$ Monopoly $>$ Cournot $>$ Bertrand $(\delta=0.90)$ & 0.001 & 0.006 & 0.000 & 0.000 & 0.000 & 0.000 \\
\hline Monopoly $>$ Cournot $>$ Stackelberg $>$ Bertrand $(\delta=0.95)$ & 0.974 & 0.883 & 1.000 & 0.998 & 0.987 & 0.967 \\
\hline Monopoly $>$ Stackelberg $>$ Cournot $>$ Bertrand $(\delta=0.95)$ & 0.012 & 0.084 & 0.000 & 0.000 & 0.000 & 0.000 \\
\hline Monopoly $>$ Cournot $>$ Stackelberg $>$ Bertrand $(\delta=0.99)$ & 0.996 & 0.977 & 1.000 & 1.000 & 1.000 & 0.997 \\
\hline Monopoly $>$ Stackelberg $>$ Cournot $>$ Bertrand $(\delta=0.99)$ & 0.002 & 0.018 & 0.000 & 0.000 & 0.000 & 0.000 \\
\hline Stackelberg $>$ Monopoly $>$ Cournot $>$ Bertrand $(\delta=0.99)$ & 0.001 & 0.005 & 0.000 & 0.000 & 0.000 & 0.000 \\
\hline \multicolumn{7}{|l|}{ For $2.0 \leq c \leq 2.5$} \\
\hline Monopoly $>$ Cournot $>$ Stackelberg $>$ Bertrand $(\delta=0.90)$ & 1.000 & 1.000 & 1.000 & 1.000 & 1.000 & 0.999 \\
\hline Stackelberg $>$ Monopoly $>$ Cournot $>$ Bertrand $(\delta=0.95)$ & 0.001 & 0.006 & 0.000 & 0.000 & 0.000 & 0.000 \\
\hline Monopoly $>$ Cournot $>$ Stackelberg $>$ Bertrand $(\delta=0.99)$ & 0.975 & 0.886 & 1.000 & 0.999 & 0.991 & 0.968 \\
\hline Monopoly $>$ Stackelberg $>$ Cournot $>$ Bertrand $(\delta=0.99)$ & 0.011 & 0.083 & 0.000 & 0.000 & 0.000 & 0.000 \\
\hline Stackelberg $>$ Monopoly $>$ Cournot $>$ Bertrand $(\delta=0.99)$ & 0.004 & 0.032 & 0.000 & 0.000 & 0.000 & 0.000 \\
\hline \multicolumn{7}{|l|}{ For $1.0 \leq c \leq 1.9$} \\
\hline Monopoly $>$ Cournot $>$ Stackelberg $>$ Bertrand $(\delta=0.90)$ & 0.998 & 0.983 & 1.000 & 1.000 & 1.000 & 1.000 \\
\hline Monopoly $>$ Stackelberg $>$ Cournot $>$ Bertrand $(\delta=0.90)$ & 0.002 & 0.014 & 0.000 & 0.000 & 0.000 & 0.000 \\
\hline Stackelberg $>$ Monopoly $>$ Cournot $>$ Bertrand $(\delta=0.90)$ & 0.000 & 0.003 & 0.000 & 0.000 & 0.000 & 0.000 \\
\hline Monopoly $>$ Cournot $>$ Stackelberg $>$ Bertrand $(\delta=0.95)$ & 0.999 & 1.000 & 1.000 & 1.000 & 0.999 & 0.998 \\
\hline Monopoly $>$ Stackelberg $>$ Cournot $>$ Bertrand $(\delta=0.95)$ & 0.000 & 0.000 & 0.000 & 0.000 & 0.000 & 0.000 \\
\hline Stackelberg $>$ Monopoly $>$ Cournot $>$ Bertrand $(\delta=0.90)$ & 0.004 & 0.027 & 0.000 & 0.000 & 0.000 & 0.000 \\
\hline Monopoly $>$ Cournot $>$ Stackelberg $>$ Bertrand $(\delta=0.95)$ & 0.998 & 0.985 & 1.000 & 1.000 & 1.000 & 1.000 \\
\hline Monopoly $>$ Stackelberg $>$ Cournot $>$ Bertrand $(\delta=0.95)$ & 0.002 & 0.012 & 0.000 & 0.000 & 0.000 & 0.000 \\
\hline Stackelberg $>$ Monopoly $>$ Cournot $>$ Bertrand $(\delta=0.95)$ & 0.000 & 0.003 & 0.000 & 0.000 & 0.000 & 0.000 \\
\hline Monopoly $>$ Cournot $>$ Stackelberg $>$ Bertrand $(\delta=0.99)$ & 0.999 & 1.000 & 1.000 & 1.000 & 1.000 & 0.998 \\
\hline Monopoly $>$ Stackelberg $>$ Cournot $>$ Bertrand $(\delta=0.99)$ & 0.000 & 0.000 & 0.000 & 0.000 & 0.000 & 0.000 \\
\hline Stackelberg $>$ Monopoly $>$ Cournot $>$ Bertrand $(\delta=0.99)$ & 0.000 & 0.000 & 0.000 & 0.000 & 0.000 & 0.000 \\
\hline
\end{tabular}

Note: Bertrand F1 denotes results associated with the price chosen by firm 1 in the Bertrand model, while Bertrand F2 denotes the ones associated with firm 2.

Finally, it can be seen that the magnitude of the asymmetry is greater when $\delta_{2}=0.90$ than when $\delta_{2}=0.95$ in $92.1 \%$ and $100 \%$ of the cases for firm 1 and firm 2, respectively. This result is very intuitive as it represents that when the differentiation between the two goods increases, the market power of both firms increases, and thus, by taking advantage of this situation, both firms charge prices that entail a greater magnitude of positive asymmetric cost pass-through.

\section{Conclusions}

Much of the existing literature on asymmetric cost pass-through has claimed that the standard pricing theory cannot account for this phenomenon. However, Ritz (2015) showed that under constant marginal costs, a log concave demand function is a sufficient condition for the existence of positive asymmetric pricing in the standard monopoly and Cournot models. This article follows Ritz (2015) and extend his findings to the Stackelberg and Bertrand framework. Furthermore, based on simulations, this paper compares the magnitudes of asymmetry generated in the standard economic competition models. 
Table 4. Frequency count of possible scenarios within the Bertrand model

\begin{tabular}{|c|c|c|c|c|c|c|}
\hline & $0.5 \leq \alpha \leq 5$ & $0.5 \leq \alpha \leq 1$ & $1.1 \leq \alpha \leq 2.0$ & $2.1 \leq \alpha \leq 3.0$ & $3.1 \leq \alpha \leq 4.0$ & $4.1 \leq \alpha \leq 5.0$ \\
\hline \multicolumn{7}{|l|}{$\delta_{1}=\delta_{2}=\delta$} \\
\hline For $0.1 \leq c \leq 2.5$ : Bertrand $(\delta=0.90)>$ Bertrand $(\delta=0.95)>$ Bertrand $(\delta=0.99)$ & 0.917 & 0.957 & 0.937 & 0.917 & 0.918 & 0.861 \\
\hline For $2.0 \leq c \leq 2.5:$ Bertrand $(\delta=0.90)>$ Bertrand $(\delta=0.95)>$ Bertrand $(\delta=0.99)$ & 0.831 & 0.853 & 0.840 & 0.827 & 0.884 & 0.750 \\
\hline For $0.1 \leq c \leq 0.9:$ Bertrand $(\delta=0.90)>$ Bertrand $(\delta=0.95)>$ Bertrand $(\delta=0.99)$ & 0.957 & 0.992 & 0.970 & 0.956 & 0.948 & 0.925 \\
\hline \multicolumn{7}{|l|}{$\delta_{1}=0.99, \delta_{2}=0.95$} \\
\hline For $1.0 \leq \mathrm{c} \leq 1.9$ : Bertrand F2 > Bertrand F1 & 0.708 & 0.772 & 0.751 & 0.619 & 0.716 & 0.700 \\
\hline For $0.1 \leq \mathrm{c} \leq 0.9$ : Bertrand F $2>$ Bertrand F1 & 0.776 & 0.869 & 0.774 & 0.782 & 0.716 & 0.764 \\
\hline \multicolumn{7}{|l|}{$\delta_{1}=0.99, \delta_{2}=0.90$} \\
\hline For $0.1 \leq \mathrm{c} \leq 2.5$ : Bertrand F $2>$ Bertrand F1 & 0.999 & 1.000 & 1.000 & 1.000 & 0.999 & 0.998 \\
\hline For $2.0 \leq \mathrm{c} \leq 2.5$ : Bertrand F2 $>$ Bertrand F1 & 0.998 & 1.000 & 1.000 & 0.999 & 0.998 & 0.992 \\
\hline For $0.1 \leq c \leq 2.5:$ Bertrand $(\delta 2=0.90)>$ Bertrand $(\delta 2=0.95)$ & 0.921 & 0.955 & 0.934 & 0.922 & 0.912 & 0.890 \\
\hline For $2.0 \leq c \leq 2.5$ : Bertrand $(\delta 2=0.90)>$ Bertrand $(\delta 2=0.95)$ & 0.873 & 0.870 & 0.853 & 0.915 & 0.906 & 0.819 \\
\hline For $1.0 \leq c \leq 1.9$ : Bertrand $(\delta 2=0.90)>$ Bertrand $(\delta 2=0.95)$ & 0.903 & 0.935 & 0.908 & 0.898 & 0.901 & 0.883 \\
\hline For $0.1 \leq c \leq 0.9$ : Bertrand $(\delta 2=0.90)>$ Bertrand $(\delta 2=0.95)$ & 0.952 & 0.996 & 0.979 & 0.946 & 0.925 & 0.920 \\
\hline \multicolumn{7}{|l|}{ For Firm 2 with $\delta_{1}=0.99$ : } \\
\hline For $0.1 \leq c \leq 2.5:$ Bertrand $(\delta 2=0.90)>$ Bertrand $(\delta 2=0.95)$ & 1.000 & 1.000 & 1.000 & 1.000 & 1.000 & 0.999 \\
\hline For $2.0 \leq c \leq 2.5:$ Bertrand $(\delta 2=0.90)>$ Bertrand $(\delta 2=0.95)$ & 0.999 & 1.000 & 1.000 & 1.000 & 1.000 & 0.993 \\
\hline For $1.0 \leq c \leq 1.9$ : Bertrand $(\delta 2=0.90)>$ Bertrand $(\delta 2=0.95)$ & 1.000 & 1.000 & 1.000 & 1.000 & 1.000 & 1.000 \\
\hline For $0.1 \leq c \leq 0.9:$ Bertrand $(\delta 2=0.90)>$ Bertrand $(\delta 2=0.95)$ & 1.000 & 1.000 & 1.000 & 1.000 & 1.000 & 0.999 \\
\hline
\end{tabular}

Note: Bertrand F1 denotes results associated with the price chosen by firm 1 in the Bertrand model, while Bertrand F2 denotes the ones associated with firm 2 .

The contributions of this article to the literature on the asymmetric cost pass-through are compelling. First, this paper has shown that, even with constant marginal costs, two of the classic standard economic competition models, Stackelberg with homogenous goods and Bertrand with non-homogenous goods, can account for the asymmetric pricing phenomenon in terms of magnitude just by allowing the demand function to be log-concave. Second, the simulation results indicate that the magnitude of positive asymmetric pricing is positively related to market power, which implies that the monopoly model is the most asymmetric one, followed by Cournot, Stackelberg and Bertrand. Furthermore, within the Bertrand model, cross-price demand elasticity and the difference between the goods play an important role in predicting the magnitude of asymmetry, as either a lower value of the former or a higher value of the latter, implies more market power, which translates into a greater magnitude of asymmetry

From a policy perspective, it has been shown that in a market with a log-concave demand and constant marginal costs, the mere existence of asymmetric pricing is a clear sign of a non-perfect competitive market and that the greater the magnitude of the asymmetry, the greater the market power as well. Therefore, policy authorities should consider those results, as the asymmetric price adjustment is a useful tool in understanding competition in a market. Further research for the case in which the marginal costs are non-constant remains a pending task for the future.

\section{Acknowledgements}

This paper is drawn from the Master Thesis of Ricardo Quineche Uribe at the Department of Economics, London School of Economics and Political Science (LSE). The author greatly appreciates useful comments of Dr. John Sutton (LSE), M.Sc. Toshiharu Tabuchi, and MPA Jimena Montoya. Furthermore, the author also deeply appreciates the Central Reserve Bank of Peru for awarding him a merit-based fellowship to pursue graduate studies at LSE and The University of Chicago. Any errors are responsibility of the author.

\section{References}

Bacon, R. W. (1991). Rockets and feathers: the asymmetric speed of adjustment of UK retail gasoline prices to cost changes. Energy economics, 13(3), 211-218. https://doi.org/10.1016/0140-9883(91)90022-R

Bailey, D., \& Brorsen, B. W. (1989). Price Asymmetry in Spatial Fed Cattle Markets. Western Journal of Agricultural Economics, 14(2), 246-252.

Balke, N. S., Brown, S. P. A. \& Yücel, M. K. (1998). Crude Oil and Gasoline Prices: An asymmetric Relationship? Economic and Financial Review-Federal Reserve Bank of Dallas, First Quarter, 2-11.

Blinder, A. S. (1982). Inventories and Sticky Prices: More on the Microfoundation of Macroeconomics. The American 
Economic Review, 72(3), 334-348.

Bonnet, C., \& Villas, B. S. B. (2016). An analysis of asymmetric consumer price responses and asymmetric cost pass-through in the French coffee market. European Review of Agricultural Economics, 43(5), 781-804. https://doi.org/10.1093/erae/jbw001

Borenstein, S., Cameron, A. C., \& Gilbert, R. (1997). Do Gasoline Prices respond asymmetrically to Crude Oil Price Changes?. Quarterly Journal of Economics, 112, 305-339. https://doi.org/10.1162/003355397555118

Boyd, M. S., \& Brorsen, B. W. (1988). Price asymmetry in the US pork marketing channel. North central journal of Agricultural Economics, 10(1), 103-109. https://doi.org/10.2307/1349239

Brown, S. P., \& Yucel, M. K. (2000). Gasoline and crude oil prices: why the asymmetry?. Economic \& Financial Review, Thir Quarter, 23-29.

Buckle, R. A., \& Carlson, J. A. (2000). Inflation and asymmetric Price Adjustment. Review of Economics and Statistics, 82(1), 157-160. https://doi.org/10.1162/rest.2000.82.1.157

Cabral, L., \& Fishman, A. (2012). Business as usual: A consumer search theory of sticky prices and asymmetric price adjustment. International Journal of Industrial Organization, 30(4), 371-376. https://doi.org/10.1016/j.ijindorg.2012.01.003

Hannan, T. H., \& Berger, A. N. (1991). The rigidity of prices: Evidence from the banking industry. The American Economic Review, 81(4), 938-945.

Jackson III, W. E. (1997). Market structure and the speed of price adjustments: evidence of non-monotonicity. Review of Industrial organization, 12(1), 37-57. https://doi.org/10.1023/A:1007700703448

Karrenbrock, J. D. (1991). The behavior of retail gasoline prices: symmetric or not?. Federal Reserve Bank of St. Louis Review, 73(4), 19-29. https://doi.org/10.20955/r.73.19-29

Kelley, C. T. (2003). Solving nonlinear equations with Newton's method. Philadelphia, PA: Society for Industrial and Applied Mathematics. https://doi.org/10.1137/1.9780898718898

Kinnucan, H. W., \& Forker, O. D. (1987). Asymmetry in Farm-Retail Price Transmission for major Dairy Products. American Journal of Agricultural Economics, 69, 285-292. https://doi.org/10.2307/1242278

Kouyaté, C., \& Cramon, T. S. (2016). Distance and Border Effects on Price Transmission: A Meta-analysis. Journal of Agricultural Economics, 67(2), 255-271. https://doi.org/10.1111/1477-9552.12145

Lewis, M. S. (2011). Asymmetric price adjustment and consumer search: an examination of the retail gasoline market. Journal of Economics \& Management Strategy, 20(2), 409-449. https://doi.org/10.1111/j.1530-9134.2011.00293.x

Loy, J. P., Holm, T., Steinhagen, C., \& Glauben, T. (2015). Cost pass-through in differentiated product markets: a disaggregated study for milk and butter. European Review of Agricultural Economics, 42(3), 441-471. https://doi.org/10.1093/erae/jbu031

Loy, J. P., Weiss, C. R., \& Glauben, T. (2016). Asymmetric cost pass-through? Empirical evidence on the role of market power, search and menu costs. Journal of Economic Behavior \& Organization, 123, 184-192. https://doi.org/10.1016/j.jebo.2016.01.007

Meyer, J., \& Cramon, T. S. (2004). Asymmetric price transmission: a survey. Journal of agricultural economics, 55(3), 581-611. https://doi.org/10.1111/j.1477-9552.2004.tb00116.x

Neumark, D., \& Sharpe, S. A. (1992). Market Structure and the Nature of Price Rigidity: Evidence from the Market for Consumer Deposits. Quarterly Journal of Economics, 107, 657-680. https://doi.org/10.2307/2118485

Peltzman, S. (2000). Prices Rise Faster than they Fall. Journal of Political Economy, 108, $466-502$. https://doi.org/10.1086/262126

Perdiguero, G. J. (2013). Symmetric or asymmetric oil prices? A meta-analysis approach. Energy policy, 57, $389-397$. https://doi.org/10.1016/j.enpol.2013.02.008

Pick, D. H., Karrenbrock, J., \& Carman, H. F. (1990). Price asymmetry and marketing margin behavior: An example for California-Arizona citrus. Agribusiness, $\quad 6(1), \quad 75-84$. https://doi.org/10.1002/1520-6297(199001)6:1<75::AID-AGR2720060108>3.0.CO;2-P

Reagan, P. B., \& Weitzman, M. L. (1982). Asymmetries in price and quantity adjustments by the competitive firm. Journal of Economic Theory, 27(2), 410-420. https://doi.org/10.1016/0022-0531(82)90037-0

Richards, T. J., Gómez, M. I., \& Lee, J. (2014). Pass-through and consumer search: An empirical analysis. American Journal of Agricultural Economics, 96(4), 1049-1069. https://doi.org/10.1093/ajae/aau009 
Ritz, R. A. (2015). The Simple Economics of Asymmetric Cost Pass-Through (CEEPR WP 2015-009). Retrieved from MIT Center for Energy and Environmental Policy Research website: http://ceepr.mit.edu/files/papers/2015-009.pdf

Tappata, M. (2009). Rockets and feathers: Understanding asymmetric pricing. The RAND Journal of Economics, 40(4), 673-687. https://doi.org/10.1111/j.1756-2171.2009.00084.x

Verlinda, J. A. (2008). Do rockets rise faster and feathers fall slower in an atmosphere of local market power? Evidence from the retail gasoline market. The Journal of Industrial Economics, 56(3), 581-612. https://doi.org/10.1111/j.1467-6451.2008.00351.x

Ward, R. W. (1982). Asymmetry in Retail, Wholesale and Shipping Point Pricing for fresh Vegetables. American Journal of Agricultural Economics, 62, 205-212. https://doi.org/10.2307/1241124

Yang, H., \& Ye, L. (2008). Search with learning: understanding asymmetric price adjustments. The RAND Journal of Economics, 39(2), 547-564. https://doi.org/10.1111/j.0741-6261.2008.00027.x

\section{Notes}

Note 1 . This term refers to the fact that prices rise like rockets but fall like feathers in response to identically-sized changes in costs.

Note 2. The asymmetry can be also negative when as a response to identically-sized changes in costs, prices rise less strongly or slower than they fall. This is also known as the Edgeworth's taxation paradox.

Note 3. From now on, standard economic competition models include: monopoly, Cournot with homogenous goods, Stackelberg with homogenous goods and Bertrand with non-homogenous goods.

Note 4. Since the Persian Gulf crisis, the literature has concentrated most of its efforts on analysing the response of gasoline prices to changes in world oil prices Since the Persian Gulf crisis, the literature has concentrated most of its efforts on analysing the response of gasoline prices to changes in world oil prices.

Note 5. For further details on this literature, see Meyer and Cramon-Taubadel (2004)

Note 6. "prices are sticky downward because when input prices fall the old output price offers a natural focal point for oligopolistic sellers" (Borenstein et al., 1997, p. 324).

Note 7. For further details, see Heien (1980), Buckle and Carson (2000), Balke et al. (1998), Blinder (1982), and Reagan and Weiztman (1982).

Note 8 . These models with consumer search costs were previously suggested by some empirical studies (Borenstein et al., 1997). For an empirical analysis of these models, see Richards, Gómez and Lee (2014).

Note 9. Ritz (2015) also showed that under perfect competition, asymmetric price arises if the market demand curve is convex and the supply curve is concave in price. However, this requires non-constant marginal cost, which is a case that is outside the range of analysis of this paper.

Note 10. One must take into account that when differentiating with respect to $\mathrm{c}$, in equilibrium the price of the other good is a function of $\mathrm{c}$ as well.

Note 11. For further detail about the Newton-Raphson method, see Kelley (2003).

Note 12. Even though the Bertrand model can lead us to two prices, a comparison between all these models can be made, as we are in the Bertrand case with $\delta_{1}=\delta_{2}$, so there is no differentiation in the goods produced by both firms, and therefore a unique price arises.

Note 13. If not, as the asymmetric coefficient is an absolute value, by construction it would allow comparison between the magnitudes of positive and negative asymmetry.

Note 14. It is a very well-known theoretical result that the price charged in a monopoly setting is the highest, followed by Cournot and Stackelberg, both with two firms, respectively.

Note 15. The difference that remains is the existence of a cross-price demand elasticity in the Bertrand model.

\section{Copyrights}

Copyright for this article is retained by the author(s), with first publication rights granted to the journal.

This is an open-access article distributed under the terms and conditions of the Creative Commons Attribution license which permits unrestricted use, distribution, and reproduction in any medium, provided the original work is properly cited. 